\title{
Unraveling the Fluorescence Features of Individual Corrole NH Tautomers
}

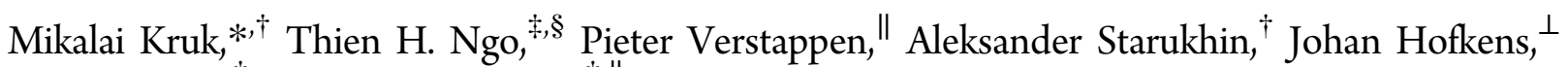
Wim Dehaen, ${ }^{\ddagger}$ and Wouter Maes $*, \neq, \|$

${ }^{\dagger}$ B. I. Stepanov Institute of Physics of National Academy of Sciences, Pr. Nezavisimosti 68, Minsk 220072, Belarus

${ }^{\ddagger}$ Molecular Design and Synthesis, Department of Chemistry, KU Leuven, Celestijnenlaan 200F, B-3001 Leuven, Belgium

${ }^{\S}$ Institut für Chemie und Biochemie-Organische Chemie, Freie Universität Berlin, Takustrasse 3, D-14195 Berlin, Germany

"Design \& Synthesis of Organic Semiconductors (DSOS), Institute for Materials Research (IMO-IMOMEC), Hasselt University, Universitaire Campus, Agoralaan 1, Building D, B-3590 Diepenbeek, Belgium

${ }^{\perp}$ Molecular Imaging and Photonics, Department of Chemistry, KU Leuven, Celestijnenlaan 200F, B-3001 Leuven, Belgium

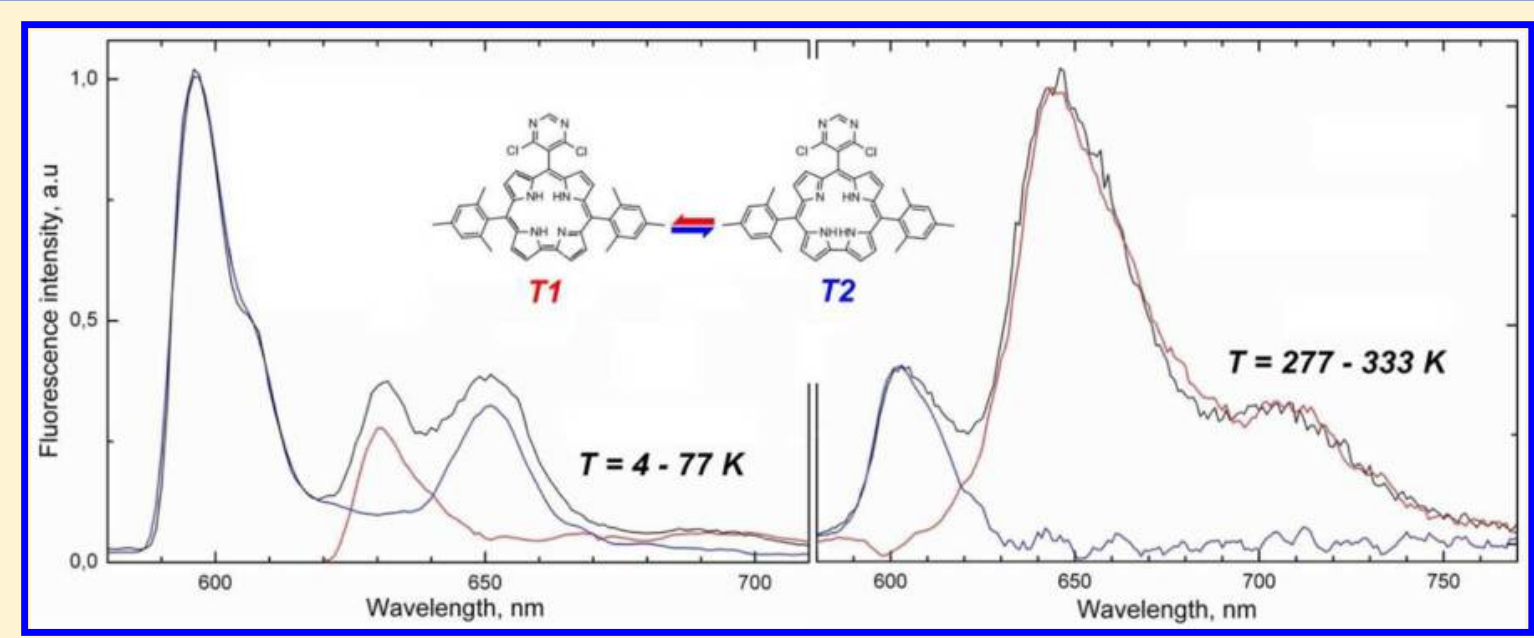

ABSTRACT: The fluorescence spectra of 10-(4,6-dichloropyrimidin-5-yl)-5,15-dimesitylcorrole have been studied in the temperature range from 4.2 to $332 \mathrm{~K}$. For the first time, the individual fluorescence profiles of the two corrole $\mathrm{NH}$ tautomers have been assigned over the whole temperature range. The pronounced temperature dependence of the fluorescence spectra of the meso-pyrimidinylcorrole under study was found to originate from switching between the fluorescence emissions of the two tautomers due to a reduced $\mathrm{NH}$ tautomerization rate with decreasing temperature. As a result, the long wavelength tautomer dominates the total emission spectrum at room temperature, whereas at low temperatures, the majority of the emission comes from the short wavelength tautomer. Energy level diagrams (involving the two NH tautomers) explaining the excitation energy deactivation channels in the meso-pyrimidinylcorrole at room temperature and below are presented. A significant H/D isotope effect on the $\mathrm{NH}$ tautomerization rate has been observed, resulting in an enhanced contribution of the short wavelength tautomer to the total fluorescence spectrum at the expense of that of the long wavelength tautomer. Substantially different fluorescence quantum yields have been determined for the individual $\mathrm{NH}$ tautomers, leading to a pronounced temperature dependence of the overall fluorescence quantum yield. The obtained results allow the unambiguous statement that the two $\mathrm{NH}$ tautomers of corroles coexist in fluid and solid solutions in a wide range of temperatures, with the proportion depending on the corrole substitution pattern. Moreover, this study shows that the (future) interpretation of the fluorescence properties of mesopyrimidinylcorroles and all other corrole materials should be done (more) carefully, taking into account the coexistence of $\mathrm{NH}$ tautomers with individual spectral signatures.

\section{INTRODUCTION}

Corroles, contracted porphyrin analogues lacking one mesocarbon atom, represent a unique family of chromophores with distinct structural, chemical, and photophysical properties, which makes them promising compounds for the construction of functional architectures designed for specific applications in the fields of optoelectronics, solar energy conversion, biological chemistry, catalysis, medicine, and sensors. ${ }^{1,2}$ Rapid progress in corrole research during the past decade has been initiated and facilitated by the introduction of new high-yielding synthetic

Received: May 31, 2012

Revised: July 13, 2012

Published: September 17, 2012 


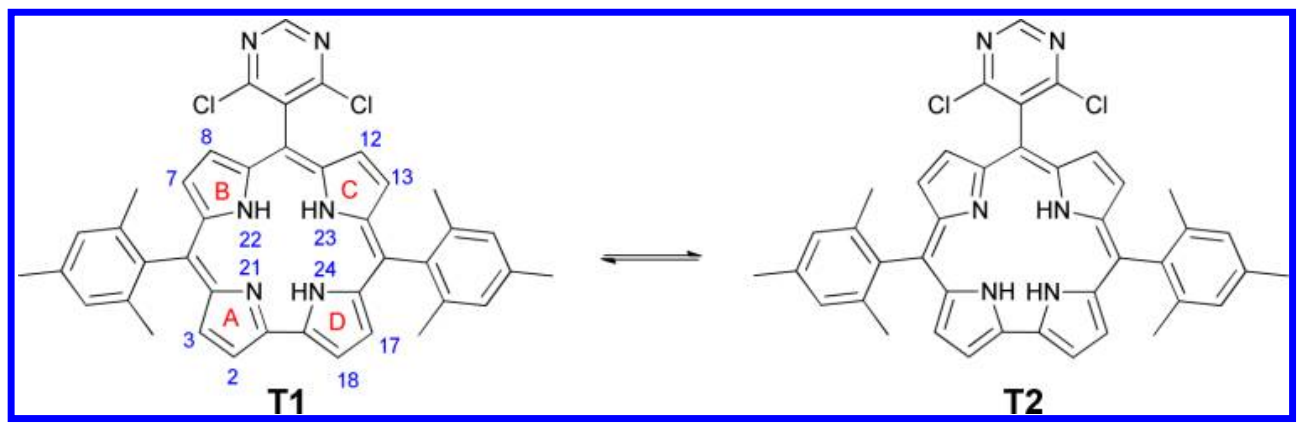

Figure 1. Equilibrium showing the two NH tautomers of free-base 10-(4,6-dichloropyrimidin-5-yl)-5,15-dimesitylcorrole (with corrole numbering scheme; $\mathrm{T} 1$ and $\mathrm{T} 2$ are tentatively assigned).

procedures for triarylcorroles. ${ }^{3}$ Studies of the photophysical properties of these compounds and the relationship between the molecular structures and the fluorescence and ground state absorption features have received only minor attention. ${ }^{4}$ The fluorescence quantum yields $\Phi_{\mathrm{fl}}$ and lifetimes, ${ }^{4 \mathrm{a}-\mathrm{s}}$ and the intersystem crossing quantum yields $\Phi_{\text {ISC }}$ and photosensitized formation of singlet molecular oxygen ${ }^{4 \mathrm{f}, \mathrm{o}, \mathrm{p}}$ have been reported for a few corroles (mainly triaryl-substituted). More recently, the photophysical properties of a series of free-base $(\mathrm{Fb})$ mesopyrimidinylcorroles have been explored, ${ }^{5}$ and the relationship of the excitation energy deactivation pathways with the substitution pattern and internal heavy atom effects has been studied in detail. ${ }^{5 c, e}$ Only a few attempts for the rationalization of the photophysical properties of $\mathrm{Fb}$ meso-triarylcorroles have been undertaken so far. ${ }^{1 \mathrm{~d}, 4 \mathrm{e}, \mathrm{f}}$

In a preceding article, we have identified the individual features of the two $\mathrm{NH}$ tautomers of a meso-pyrimidinylcorrole in the ground state absorption spectra and demonstrated the difference in their basicity, resulting in two stages in the experimentally derived protonation curve. ${ }^{6}$ As far as two $\mathrm{NH}$ tautomer species coexisting, the photophysical properties of the sample solution can be highly influenced by the $\mathrm{NH}$ tautomer equilibrium, and, first of all, two different emission spectra are expected belonging to the individual corrole $\mathrm{NH}$ tautomers. None of the above cited papers reporting on the photophysical properties of corroles ${ }^{4}$ considered the possibility that the reported experimentally derived features might result from (or might be influenced by) two coexisting corrole $\mathrm{NH}$ tautomers. In this article, we provide, for the first time, unambiguous experimental proof for the coexistence of two corrole $\mathrm{NH}$ tautomers in solution in a wide range of temperatures, focusing on a representative material of the meso-pyrimidinylcorrole family, i.e., 10-(4,6-dichloropyrimidin-5-yl)-5,15-dimesitylcorrole (Figure 1), and applying ground state absorption spectroscopy and steady-state fluorescence spectroscopy in the temperature range $4.2-332 \mathrm{~K}$.

\section{EXPERIMENTAL AND THEORETICAL METHODS}

10-(4,6-Dichloropyrimidin-5-yl)-5,15-dimesitylcorrole was prepared in accordance with a previously published synthetic procedure. ${ }^{5 a}$ All solvents were of spectroscopic grade and were used as received (Sigma-Aldrich, Merck, Acros Organics). Ground state absorption spectra were measured with a UV-vis Varian Carry 100 spectrophotometer in standard quartz rectangular cells $(1 \times 1 \mathrm{~cm}$, Hellma). The measurements of the spectra at $77 \mathrm{~K}$ were done with a cryogenic quartz holder. The fluorescence spectra and fluorescence excitation spectra at room temperature were measured with the use of a spectrofluorometer SFL-1211 (Solar, Belarus) or SPEX
Fluorolog 1500. Low temperature (4.2 and $77 \mathrm{~K}$ ) fluorescence measurements were carried out for samples placed in a helium cryostat with a home-built luminescence spectrometer based on a DFS-24 monochromator. ${ }^{7}$ The fluorescence was excited by either a Nd:YAG (LS-2115-LOTIS-TII, Belarus) pumped tunable dye laser or UV emitting diodes (Nichia, $\lambda_{\text {peak }}=385$ and $405 \mathrm{~nm}, \Delta \lambda=20.0 \mathrm{~nm}$ ). The signal was recorded with a two-channel oscilloscope unit BORDO 220 that was integrated in the spectral data acquisition complex Helios-1.43. All emission spectra were corrected for spectral sensitivity using the radiation of a tungsten lamp (Osram WI-14). The fluorescence quantum yields $\Phi_{\mathrm{fl}}$ were determined using the standard sample method, with free-base 5,10,15,20-tetraphenylporphyrin (TPP) as a standard sample $\left(\Phi_{\mathrm{fl}}^{0}=0.09^{8}\right)$. Corrole concentrations in solution were measured spectrophotometrically with preliminarily determined extinction coefficients at $298 \mathrm{~K}\left(\lambda_{\max }, \mathrm{nm} / \log \varepsilon, \mathrm{M}^{-1} \mathrm{~cm}^{-1}\right): 410 / 5.02,427 /$ 4.92, 570/4.30, 599/4.05, and 635/3.28 in EtOH/EtOD and $410 / 5.03,427 / 4.92,570 / 4.34,599 / 4.06$, and $635 / 3.28$ in 2 Me-THF. No sign of aggregation was found for a corrole concentration range up to $6.0 \times 10^{-5} \mathrm{M}$, wherein all experiments were carried out.

\section{RESULTS AND DISCUSSION}

Fluorescence Spectra at Room Temperature. The fluorescence and ground-state absorption spectra for $\mathrm{Fb} 10$ (4,6-dichloropyrimidin-5-yl)-5,15-dimesitylcorrole (hereafter referred to as $\mathrm{H}_{3} \mathrm{AB}_{2}$-corrole) in $\mathrm{EtOH}$ and 2-Me-THF at $293 \mathrm{~K}$ are shown in Figure 2. One can see that the shapes of both the absorption and fluorescence spectra measured in $\mathrm{EtOH}$ and 2-Me-THF are practically indistinguishable. As we have demonstrated recently, ${ }^{6}$ the two $\mathrm{NH}$ tautomers of the $\mathrm{H}_{3} \mathrm{AB}_{2}$-corrole coexist in comparable concentrations in solution at room temperature, and the absorption spectrum results from the superimposed spectra of the two tautomers. In the Soret range, the bands with maxima at 410 and $427 \mathrm{~nm}$ belong to the $\mathrm{NH}$ tautomers, hereafter referred to as the T2 (shortwavelength) and T1 (long-wavelength) tautomers, respectively. The weak band at $634 \mathrm{~nm}$ was assigned to the $\mathrm{S}_{0}(0,0) \rightarrow$ $S_{1}(0,0)$ transition of the $\mathrm{T} 1$ tautomer. An average energy difference of $935 \pm 10 \mathrm{~cm}^{-1}$ was found for the transitions belonging to the two $\mathrm{NH}$ tautomers in the Soret region in four different solvents $\left(\mathrm{CH}_{2} \mathrm{Cl}_{2}, \mathrm{EtOH}, 2-\mathrm{Me}-\mathrm{THF}\right.$, and $\left.\mathrm{MeCN}\right)$, and the same difference in energy $\left(940 \pm 10 \mathrm{~cm}^{-1}\right)$ was measured for the long wavelength transitions with bands peaking at $\sim 599$ and $634 \mathrm{~nm}$. This finding allows to assign the band at $599 \mathrm{~nm}$ to the $S_{0}(0,0) \rightarrow S_{1}(0,0)$ transition of the T2 tautomer. The assignment of all the bands in the absorption 


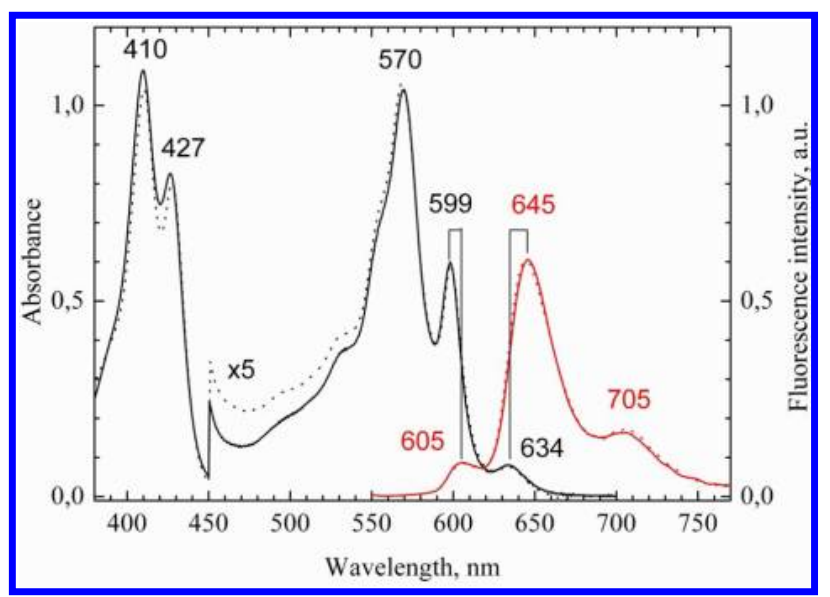

Figure 2. Absorption and fluorescence spectra of $\mathrm{Fb}$ mesopyrimidinylcorrole $\mathrm{H}_{3} \mathrm{AB}_{2}$ at $T=293 \mathrm{~K}$. Absorption spectra were measured in EtOH (black dashed line) and 2-Me-THF (black solid line $)$ in equimolar concentrations $\left(C=9.6 \times 10^{-6} \mathrm{M}\right)$. Fluorescence spectra $\left(\lambda_{\text {exc }}=470 \mathrm{~nm}\right)$ in EtOH (red dashed line) and 2-Me-THF (red solid line) are scaled to the same peak intensity as for the absorbance at $599 \mathrm{~nm}$. Thin solid lines indicate the $S_{0} \rightarrow S_{1}$ absorption bands and the corresponding $S_{1} \rightarrow S_{0}$ fluorescence bands for the T1 and T2 tautomer $(634 / 645 \mathrm{~nm}$ and $599 / 605 \mathrm{~nm}$, respectively). All peak values refer to the spectra measured in 2-Me-THF.

spectrum to the individual $\mathrm{NH}$ tautomer spectra is given in a separate forthcoming article. ${ }^{9}$

It is of great interest to make such a detailed assignment for the fluorescence spectrum of the $\mathrm{H}_{3} \mathrm{AB}_{2}$-corrole as well. The fluorescence spectra (Figure 2) bear the same features as reported earlier for the families of $\mathrm{AB}_{2^{-}}, \mathrm{A}_{2} \mathrm{~B}-$, and $\mathrm{A}_{3^{-}}$ pyrimidinylcorroles, ${ }^{5 c, e}$ as well as those for several other triarylcorrole derivatives. $^{4 \mathrm{e}, \mathrm{f}, \mathrm{p}}$ More specifically, a weak band centered at $605 \mathrm{~nm}$ and two strong bands with maxima at 645 and $705 \mathrm{~nm}$ were found. The most prominent band at $645 \mathrm{~nm}$ should be assigned to the $S_{1}(0,0) \rightarrow S_{0}(0,0)$ fluorescence transition of the T1 tautomer. The Stokes shift value is 270 $\mathrm{cm}^{-1}$, which is in line with values reported for several other triarylcorrole derivatives $\left(250-490 \mathrm{~cm}^{-1}\right){ }^{4 \mathrm{e}, \mathrm{f}}$ The peak at 705 $\mathrm{nm}$ should be attributed to the vibronic band $S_{1}(0,0) \rightarrow S_{0}(1,0)$ belonging to the fluorescence spectrum of the long wavelength $\mathrm{T} 1$ tautomer. The energy of this vibronic progression is $1300 \pm$ $25 \mathrm{~cm}^{-1}$, which fits well to the reported vibronic progression for different triarylcorrole derivatives, ranging from 1150 to 1380 $\mathrm{cm}^{-1}$. ${ }^{\mathrm{e}, \mathrm{f}}$ The energy difference of $1025 \mathrm{~cm}^{-1}$ between the two fluorescence bands with maxima at 605 and $645 \mathrm{~nm}$ is close to that observed for the $S_{0}(0,0) \rightarrow S_{1}(0,0)$ transitions of the two $\mathrm{NH}$ tautomers in the absorption spectrum $\left(940 \mathrm{~cm}^{-1}\right)$. This gives a basis to suggest that these two peaks at 605 and $645 \mathrm{~nm}$ in the fluorescence spectrum of the $\mathrm{H}_{3} \mathrm{AB}_{2}$-corrole are due to the $S_{1}(0,0) \rightarrow S_{0}(0,0)$ transitions of the two separate tautomers. Indeed, the Stokes shift value is $165 \mathrm{~cm}^{-1}$ in this case, i.e., relaxation of the $S 1$ state is smaller for the T2 tautomer. With the same value of vibronic progression energy, the position of the vibronic $S_{1}(0,0) \rightarrow S_{0}(1,0)$ band of the T2 tautomer can be estimated around $657 \mathrm{~nm}$. Suggesting the same intensity ratio of the electronic to vibronic band as for the $\mathrm{T} 1$ tautomer $(I(645 \mathrm{~nm}) / I(705 \mathrm{~nm})=3.7)$, the intensity of the band at $657 \mathrm{~nm}$ should be more than 30 times smaller than for the band at $645 \mathrm{~nm}$. Therefore, it is not surprising that it is not visible here, and as a result, the total fluorescence spectrum consists of only three bands for the two $\mathrm{NH}$ tautomers instead of the expected four.

Stokes shift values of $80-260$ and $250-340 \mathrm{~cm}^{-1}$ were calculated for the $\mathrm{T} 2$ and $\mathrm{T} 1$ tautomers of different mesopyrimidinylcorroles, respectively, based on previously published data in different solvents at room temperature. ${ }^{5 c, e}$ These figures allow to suggest that conformational relaxation of the molecule in the excited state is involved, as it occurs for the highly flexible diprotonated tetraphenylporphyrin and other nonplanar porphyrins. ${ }^{8,10}$ It is worthwhile to note that the Stokes shift value is higher for the $\mathrm{T} 1$ tautomer for all corroles and also if the same corrole is considered in different solvents, indicating that the T1 tautomer structure undergoes slightly larger rearrangements in the excited singlet $S_{1}$ state as compared to the $\mathrm{T} 2$ tautomer.

One additional important feature of the fluorescence spectrum of the $\mathrm{H}_{3} \mathrm{AB}_{2}$-corrole should be stressed. One can see that the majority of the emission comes from the T1 tautomer and that fluorescence from the T2 tautomer has only a minor contribution. This is in contrast with the ground state distribution of the two $\mathrm{NH}$ tautomers, where the T2 tautomer proportion is likely to be higher than $50 \%$, as can be seen from the trend in the absorbance changes upon going from 293 to 77 $\mathrm{K}$ (Figures 2 and 3). Both facts taken together indicate that

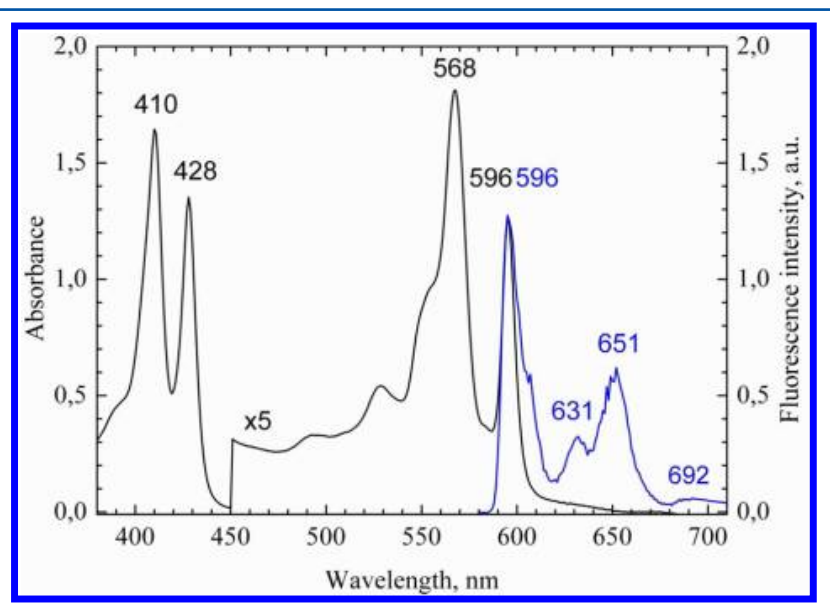

Figure 3. Absorption and fluorescence spectra of $\mathrm{Fb}$ mesopyrimidinylcorrole $\mathrm{H}_{3} \mathrm{AB}_{2}$ at $T=77 \mathrm{~K}$. The absorption spectrum was measured in 2-Me-THF (black solid line; $C=9.6 \times 10^{-6} \mathrm{M}$ ). The fluorescence spectrum (blue solid line; $\lambda_{\text {exc }}=385 \mathrm{~nm}$ ) was scaled to the same peak intensity for the absorbance and fluorescence bands at $596 \mathrm{~nm}$. For both the T1 and the T2 tautomer, the peak positions of the $S_{0} \rightarrow S_{1}$ absorption band and the corresponding $S_{1} \rightarrow S_{0}$ fluorescence band are the same: 631 and $596 \mathrm{~nm}$, respectively. The absorption band at $631 \mathrm{~nm}$ is too weak to be visible at this scale.

efficient $\mathrm{T} 2 \rightarrow \mathrm{T} 1$ tautomerization takes place in the excited singlet $S_{1}$ state for the $\mathrm{H}_{3} \mathrm{AB}_{2}$-corrole, leading to preferential population of the $S_{1}$ state of the T1 tautomer. Back T1 $\rightarrow$ T2 tautomerization in the excited $S_{1}$ state seems to be inefficient since the energy barrier for tautomerization in this direction is about $1000 \mathrm{~cm}^{-1}$.

Fluorescence Spectra at Low Temperature. The fluorescence and ground-state absorption spectra for the $\mathrm{H}_{3} \mathrm{AB}_{2}$-corrole in 2-Me-THF at $77 \mathrm{~K}$ are shown in Figure 3. When comparing the long wavelength range of the absorption spectra at 293 and $77 \mathrm{~K}$, one can see that the band of the T1 tautomer at $634 \mathrm{~nm}$ practically disappears. In the visible range, where the long wavelength $\mathrm{T} 1$ tautomer has absorption bands, 
the absorbance also decreases. Apparently, all these spectral changes are due to a decrease in the proportion of the long wavelength $\mathrm{T} 1$ tautomer when temperature drops. Thus, the majority of the $\mathrm{H}_{3} \mathrm{AB}_{2}$-corrole is present as the $\mathrm{T} 2$ tautomer at $77 \mathrm{~K}$.

The fluorescence spectrum measured at $77 \mathrm{~K}$ also undergoes pronounced changes as compared with that measured at room temperature. Such dramatic changes in the fluorescence spectra for several $\mathrm{Fb}$ meso-pyrimidinylcorroles upon going from room temperature down to $77 \mathrm{~K}$ have been noticed by us earlier on, but the origin of these changes remained to be established. ${ }^{\text {sc }}$ Thus, three maxima were observed in the fluorescence spectrum of the $\mathrm{H}_{3} \mathrm{AB}_{2}$-corrole in 2-Me-THF, but now it is the low wavelength band centered at $596 \mathrm{~nm}$ that dominates in the spectrum. Comparing this value with that for the $S_{0}(0,0) \rightarrow$ $\mathrm{S}_{1}(0,0)$ transition in the absorption spectrum of the $\mathrm{T} 2$ tautomer $(596 \mathrm{~nm})$, one can conclude that this peak belongs to the $S_{1}(0,0) \rightarrow S_{0}(0,0)$ transition of the T2 tautomer. The emission and absorbance spectra maxima are essentially the same, giving rise to emission from the Franck-Condon state without any relaxation. The rigid environment in solid solution at low temperatures prevents the relaxation processes. These findings constitute one additional noteworthy feature of the fluorescence spectra of the $\mathrm{H}_{3} \mathrm{AB}_{2}$-corrole, and the family of pyrimidinylcorroles as a whole, at low temperatures, namely, the absence of a noticeable Stokes shift between the absorption and fluorescence maxima. The band with maximum at $651 \mathrm{~nm}$ should be assigned as a vibrational satellite of the $596 \mathrm{~nm}$ band as the energy difference corresponds to that for a vibronic progression. The vibrational progression energy is $1410 \pm 25$ $\mathrm{cm}^{-1}$ and is slightly higher than what was found at $293 \mathrm{~K}$. This is because the vibronic band is due to superposition of a large set of vibrational modes, and changes in both the vibrational modes half width and the intensity of the phonon wings can result in a slight shift of the overall maximum in the total fluorescence spectrum.

At low temperatures, the fluorescence of the $\mathrm{T} 1$ tautomer also occurs without noticeable Stokes shift. Suggesting the same blue shift of the $S_{0}(0,0) \rightarrow S_{1}(0,0)$ absorption band of the T1 tautomer with temperature as for the T2 tautomer $\left(\sim 90 \mathrm{~cm}^{-1}\right)$, the band should have a maximum at $631 \mathrm{~nm}$. Thus, the maximum at $631 \mathrm{~nm}$ in the fluorescence spectra corresponds to the $S_{1}(0,0) \rightarrow S_{0}(0,0)$ transition of the T1 tautomer. The weak diffuse band centered around $\sim 692 \mathrm{~nm}$ in the fluorescence spectrum at $77 \mathrm{~K}$ can then be explained as a vibronic $S_{1}(0,0) \rightarrow$ $\mathrm{S}_{0}(1,0)$ band in the fluorescence spectrum of the T1 tautomer.

No spectral differences were revealed at room temperature upon a change of the excitation wavelength. When the fluorescence excitation spectra were recorded, there was also no difference upon change of the emission wavelength. This is due to very efficient thermal repopulation between the two $\mathrm{NH}$ tautomers and a strong overlap of their absorption spectra. On the contrary, the fluorescence excitation spectra measured at 77 $\mathrm{K}$ revealed significant differences when the fluorescence emission was collected in the $S_{1} \rightarrow S_{0}$ maxima of the two $\mathrm{NH}$ tautomers, i.e., at $596 \mathrm{~nm}$ for the T2 tautomer and $631 \mathrm{~nm}$ for the T1 tautomer (Figure 4). Differences in the fluorescence excitation profiles were observed in both the visible and Soret band ranges, with the latter being especially pronounced. One can see that both spectra contain bands belonging to the absorption of the two $\mathrm{NH}$ tautomers, likely due to some (expected) tautomerization in the excited states. However, the shape of the fluorescence excitation spectrum in the Soret band

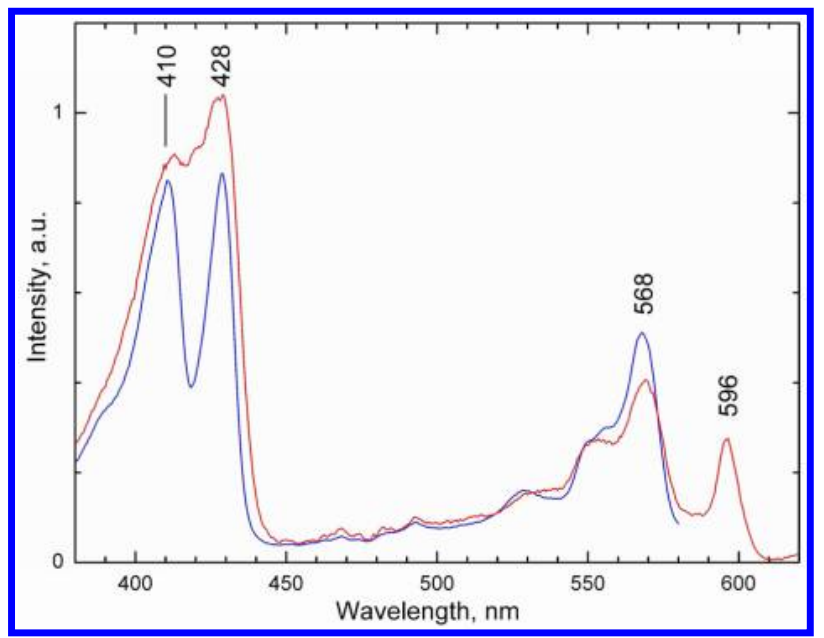

Figure 4. Fluorescence excitation spectra of $\mathrm{Fb}$ meso-pyrimidinylcorrole $\mathrm{H}_{3} \mathrm{AB}_{2}$ in 2-Me-THF at $T=77 \mathrm{~K}$. The spectra were measured with emission collection at the respective $S_{1} \rightarrow S_{0}$ maxima of the fluorescence spectra: at $\lambda_{\mathrm{em}}=596 \mathrm{~nm}$ for the T2 tautomer (blue solid line) and at $\lambda_{\mathrm{em}}=631 \mathrm{~nm}$ for the T1 tautomer (red solid line). The spectrum measured with $\lambda_{\mathrm{em}}=631 \mathrm{~nm}$ was multiplied by a factor of 5 to achieve comparable peak intensities in the Soret region.

region is substantially different in the two cases. When the emission for the T2 tautomer was collected (at $596 \mathrm{~nm}$ ), both the bands at 410 and $428 \mathrm{~nm}$ (belonging to the T2 and T1 tautomer, respectively) are clearly visible. When the emission of the $\mathrm{T} 1$ tautomer was measured (at $631 \mathrm{~nm}$ ), the corresponding $\mathrm{T} 1$ tautomer Soret band (centered at $428 \mathrm{~nm}$ ) dominated in the fluorescence excitation spectrum since no $\mathrm{T} 1 \rightarrow \mathrm{T} 2$ tautomerization is expected. The residual bands observed in the fluorescence excitation spectra are due to minor emission of the $\mathrm{T} 2$ tautomer at the given wavelength. Thus, the fluorescence excitation spectra support once more the assignment of the bands at 410 and $428 \mathrm{~nm}$ to the different corrole $\mathrm{NH}$ tautomers. ${ }^{6}$

At low temperatures, where the $\mathrm{NH}$ tautomerization is substantially slowed down, we were able to achieve a difference in the fluorescence spectra measured at different excitation wavelengths. The fluorescence spectra of the $\mathrm{H}_{3} \mathrm{AB}_{2}$-corrole in 2-Me-THF at $4.2 \mathrm{~K}$ are shown in Figure 5. The spectrum measured with $\lambda_{\mathrm{exc}}=385 \mathrm{~nm}$ is essentially the same as was obtained with the same excitation wavelength at $77 \mathrm{~K}$. In the fluorescence spectrum of the same sample measured with $\lambda_{\mathrm{exc}}=$ $405 \mathrm{~nm}$, however, the intensity of the $\mathrm{S} 1(0,0) \rightarrow \mathrm{S} 0(0,0)$ transition of the $\mathrm{T} 1$ tautomer at $631 \mathrm{~nm}$ increases noticeably, indicating that a higher number of $\mathrm{T} 1$ tautomer molecules is excited at the expense of the $\mathrm{T} 2$ tautomer. When the two spectra are normalized for peak intensity of the band at $651 \mathrm{~nm}$, meaning the same emission signal from the T2 tautomer, the difference of the two spectra $I\left(\lambda_{\text {exc }}=405 \mathrm{~nm}\right)-I\left(\lambda_{\text {exc }}=385\right.$ $\mathrm{nm}$ ) shows the fluorescence profile for the T1 tautomer (for the sake of clarity, only the part of the spectrum in the range $620-720 \mathrm{~nm}$ is shown in Figure 5 for $\lambda_{\text {exc }}=405 \mathrm{~nm}$ ). The obtained spectrum of the T1 tautomer at $4.2 \mathrm{~K}$ bears all the spectral features as derived above from the analysis of the total fluorescence spectrum of the $\mathrm{H}_{3} \mathrm{AB}_{2}$-corrole at $77 \mathrm{~K}$.

The study of the $\mathrm{NH}$ phototautomerization mechanism in pyrimidinylcorroles is out of the scope of the given study and deserves separate consideration. Nevertheless, we can note here that repeated measurements of the fluorescence spectra of the sample at $4.2 \mathrm{~K}$, keeping the same excitation wavelength, did 


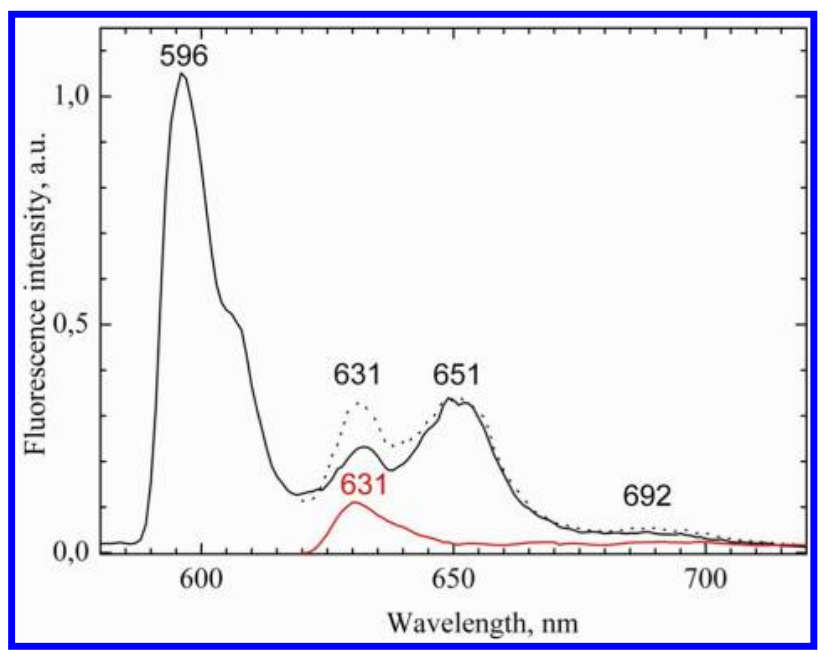

Figure 5. Fluorescence spectrum of $\mathrm{Fb}$ meso-pyrimidinylcorrole $\mathrm{H}_{3} \mathrm{AB}_{2}$ in 2-Me-THF at $T=4.2 \mathrm{~K}$ (black solid line; $\lambda_{\text {exc }}=385 \mathrm{~nm}$ ). The dotted line represents the fluorescence spectrum of the same sample in the range $620-720 \mathrm{~nm}$ with $\lambda_{\mathrm{exc}}=405 \mathrm{~nm}$ (the spectrum is normalized for equal peak intensity of the band at $651 \mathrm{~nm}$ ). The red line shows the fluorescence spectrum of the T1 tautomer at $4.2 \mathrm{~K}$, obtained as the difference of the two previous spectra: $I\left(\lambda_{\text {exc }}=405\right.$ $\mathrm{nm})-I\left(\lambda_{\text {exc }}=385 \mathrm{~nm}\right)$.

not reveal any (progressive) changes (one spectrum scan requires up to 4500 laser pulses). Since at low temperatures the majority of the $\mathrm{H}_{3} \mathrm{AB}_{2}$-corrole molecules find themselves in the $\mathrm{T} 2$ tautomer state, one can suggest that the rate of T2 $\rightarrow$ T1 phototautomerization is too slow to achieve observable changes in the $\mathrm{NH}$ tautomer proportion under the given experimental conditions.

Energy Level Diagrams. The experimental data described above allow to plot the energy level diagrams for the $\mathrm{H}_{3} \mathrm{AB}_{2}$ corrole at room temperature and $77 \mathrm{~K}$, which, taken in generalized form, should hold for the whole family of mesopyrimidinylcorroles (Figure 6). Thus, as we have shown earlier, ${ }^{6}$ the ground state energies of the two $\mathrm{NH}$ tautomers are separated for $33 \mathrm{~cm}^{-1}$ only, so the ground $S_{0}$ state population for the two tautomers should be of the same order of magnitude at $293 \mathrm{~K}$. The lowest singlet $S_{1}$ state of the long wavelength $\mathrm{T} 1$ tautomer lies more than $900 \mathrm{~cm}^{-1}$ lower compared to that of the short wavelength $\mathrm{T} 2$ tautomer and the energy difference increases slightly after $S 1$ state relaxation takes place ( 992 vs $888 \mathrm{~cm}^{-1}$ ). Thus, the activation energies for the $\mathrm{T} 1 \rightarrow \mathrm{T} 2$ and $\mathrm{T} 2 \rightarrow \mathrm{T} 1$ tautomerizations in the excited $\mathrm{S} 1$ state differ strongly, leading to preferential population of the $S_{1}$ state of the $\mathrm{T} 1$ tautomer. As a result, the fluorescence arises mainly from the $\mathrm{T} 1$ tautomer. The same behavior is expected when excitation is done with UV light in the high-lying excited states. When the $\mathrm{T} 1$ tautomer is excited, radiationless internal $S_{i} \rightarrow S_{1}$ conversion ultimately populates its $S 1$ state, whereas in the case of excitation of the T2 tautomer, the excitation energy deactivation pathway results from the competition between tautomerization and radiationless internal $S_{i} \rightarrow S_{1}$ conversion. Regardless which rate is higher, the singlet $S_{1}$ state of the long wavelength $\mathrm{T} 1$ tautomer will populate either with successive radiationless internal $S_{i} \rightarrow S_{1}$ conversion in the T2 tautomer and then $\mathrm{T} 2 \rightarrow \mathrm{T} 1$ tautomerization or with $\mathrm{T} 2 \rightarrow \mathrm{T} 1$ tautomerization in the higher excited $S_{\mathrm{i}}$ state (Soret) on the T2 tautomer followed by internal $S_{i} \rightarrow S_{1}$ conversion in the T1 tautomer.

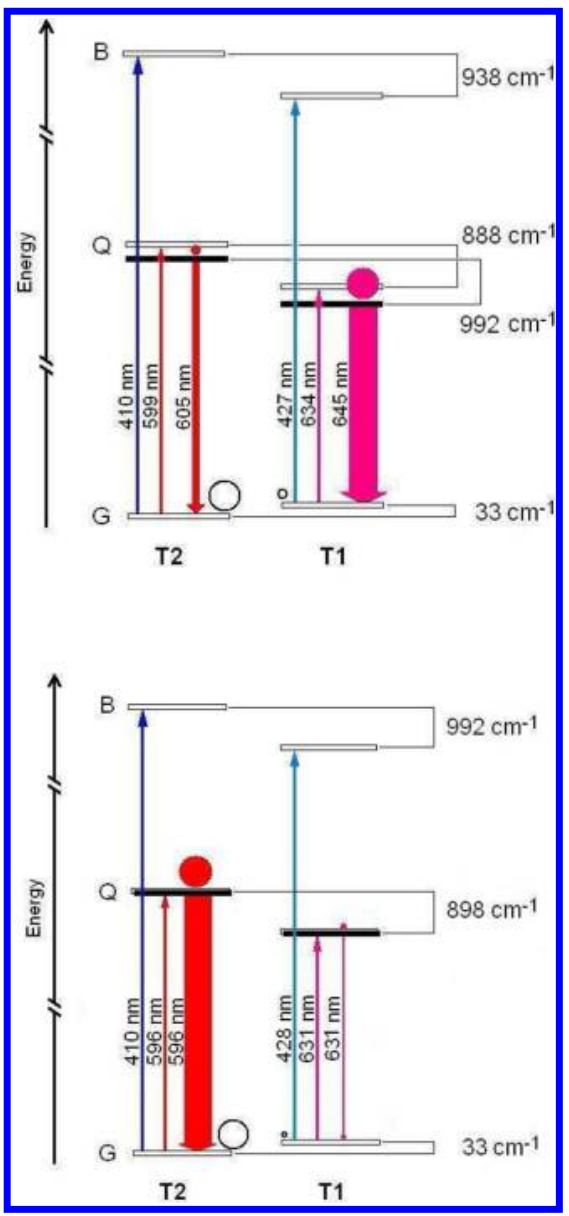

Figure 6. Simplified energy level diagram explaining the excitation and deactivation pathways for the two $\mathrm{NH}$ tautomers of $\mathrm{Fb}$ mesopyrimidinylcorrole $\mathrm{H}_{3} \mathrm{AB}_{2}$ in 2-Me-THF at $T=293 \mathrm{~K}$ (top) and $77 \mathrm{~K}$ (bottom). Circle sizes are proportional to the population of the given electronic state. Arrow widths for fluorescence reflect the relative contribution of the two NH tautomers to the total emission spectrum.

At low temperatures $(4.2-77 \mathrm{~K})$, the fluorescence spectrum of the $\mathrm{H}_{3} \mathrm{AB}_{2}$-corrole is mainly showing emission of the $\mathrm{T} 2$ tautomer, and the $\mathrm{T} 1$ tautomer fluorescence has only a minor contribution. Therefore, one can conclude that the decrease in temperature simply leads to a switching of the fluorescence between the two $\mathrm{NH}$ tautomers: in the fluorescence spectrum measured at room temperature, the $\mathrm{T} 1$ tautomer dominates, and in the spectra measured in the temperature range 4.2-77 $\mathrm{K}$, the main contribution is from the $\mathrm{T} 2$ tautomer. We should stress here that it is the fluorescence that switches (i.e., temperature controls the $\mathrm{NH}$ tautomer population ratio in the excited $S_{1}$ state, resulting in an emission deactivation switch from one tautomer to another), rather than the ground $S_{0}$ state population ratio of the two $\mathrm{NH}$ tautomers, which, as it was shown above, is only barely affected by temperature.

Thus, efficient T2 $\rightarrow \mathrm{T} 1$ tautomerization in the excited $S_{1}$ singlet state occurs at room temperature. When the temperature goes down, the probability of $\mathrm{T} 2 \rightarrow \mathrm{T} 1$ tautomerization decreases strongly, leading to conservation of the excitation energy within the $\mathrm{T} 2$ tautomer. In such a case, the photoexcitation of a sample containing the majority of molecules as T2 tautomers leads to fluorescence emission from the same $\mathrm{NH}$ tautomer. The energy level diagrams illustrate this change in the $\mathrm{T} 2 \rightarrow \mathrm{T} 1$ tautomerization 
probability in the excited $S_{1}$ state, due to which the pyrimidinylcorroles are able to operate as temperature driven fluorescence switches. We would like to stress here that this property of meso-pyrimidinylcorroles currently makes them unique within the large family of meso-triarylcorroles since (scarce) literature data available to date ${ }^{4 \mathrm{f}}$ indicate that, in other meso-triarylcorroles, including the repeatedly studied 5,10,15triphenylcorrole and 5,10,15-tris(pentafluorophenyl)corrole, the fluorescence originates from the long wavelength $\mathrm{T} 1$ tautomer both at $77 \mathrm{~K}$ and at room temperature. Only a very weak contribution from the $\mathrm{T} 2$ tautomer to the total fluorescence spectrum is expected for 5,10,15-tris(pentafluorophenyl)corrole at room temperature based on reported spectra. ${ }^{4 \mathrm{e}, \mathrm{f}}$

It is worthwhile to note that a single preferred tautomerization state at low temperature $\left(-70{ }^{\circ} \mathrm{C}\right)$ has been reported for the first time for 5,10,15-tris(pentafluorophenyl)corrole based on variable-temperature NMR. ${ }^{11}$ Decrease in temperature was found to lead to the $\mathrm{NH}$ tautomer where $\mathrm{N}(21)$ is protonated, i.e., where the unit with direct $\mathrm{C}(1)_{\alpha}-\mathrm{C}(19)_{\alpha}$ dipyrrole linkage is fully protonated (Figure 1). This result can be used to make a preliminary assignment of the observed individual absorption and fluorescence spectra to the specific tautomers $\mathrm{T} 1 / \mathrm{T} 2$ with defined positions of the protons in the macrocyclic core. It is reasonable to expect that, in the case under consideration, the majority of the molecules find themselves in the same tautomerization state at low temperature as was observed for 5,10,15-tris(pentafluorophenyl)corrole. ${ }^{11}$ Therefore, the short wavelength tautomer $\mathrm{T} 2$ can be assigned to this tautomerization state. Correspondingly, the long wavelength tautomer T1 can be assigned to the tautomerization state in which the unit with the methine $\mathrm{C}(9)_{\alpha}-\mathrm{C}(10)_{m}-\mathrm{C}(11)_{\alpha}$ bridge is fully protonated (i.e., $\mathrm{N}(22)$ is protonated). Such a tentative assignment finds support from the structure-property relationships in $\mathrm{N}$-substituted corroles at room temperature, for which it was found that the absorption spectra of the N(22)-arylsubstituted corroles are distinctly red-shifted as compared with those of the $N(21)$-aryl-substituted analogues. ${ }^{12}$ The results of detailed quantum-chemical studies also support the tentative assignment given here. ${ }^{9,13}$ Thus, one can expect that, at room temperature, fluorescence originates mainly from the $\mathrm{NH}$ tautomer with a fully protonated methine $\mathrm{C}(9)_{\alpha}-\mathrm{C}(10)_{m}-$ $\mathrm{C}(11)_{\alpha}$ bridge, whereas, at low temperature, the major emission comes from the $\mathrm{NH}$ tautomer with a fully protonated $\mathrm{C}(1)_{\alpha}-$ $\mathrm{C}(19)_{\alpha}$ dipyrrole linkage.

H/D Isotope Effect and Individual Fluorescence Spectra of the T1 and T2 Tautomers. With the aim to achieve additional information on the $\mathrm{NH}$ tautomer equilibrium in the ground $\left(\mathrm{S}_{0}\right)$ and excited $\left(\mathrm{S}_{1}\right)$ states of the $\mathrm{H}_{3} \mathrm{AB}_{2}$ corrole, we have investigated the $\mathrm{H} / \mathrm{D}$ isotope effect. It is wellknown that fast exchange of the pyrrolic protons for deuterons takes place when tetrapyrrolic compounds are dissolved in heavy water or monodeuterated alcohols, leading to formation of core-deuterated compounds. ${ }^{14}$ In the case under study, the deuterated $\mathrm{H}_{3} \mathrm{AB}_{2}$-corrole (hereafter denoted as $\mathrm{D}_{3} \mathrm{AB}_{2}$ corrole) was obtained in EtOD solution. The ground-state absorption spectrum of the $\mathrm{D}_{3} \mathrm{AB}_{2}$-corrole (not shown) was found to be essentially the same as obtained in $\mathrm{EtOH}$. However, the fluorescence spectra of the $\mathrm{D}_{3} \mathrm{AB}_{2}$-corrole revealed substantial differences as compared to those for the $\mathrm{H}_{3} \mathrm{AB}_{2}$-corrole (Figure 7). Two distinct differences should be pointed out. First of all, the proportion of the emission from the T2 tautomer (with a maximum of the $S_{1}(0,0) \rightarrow S_{0}(0,0)$

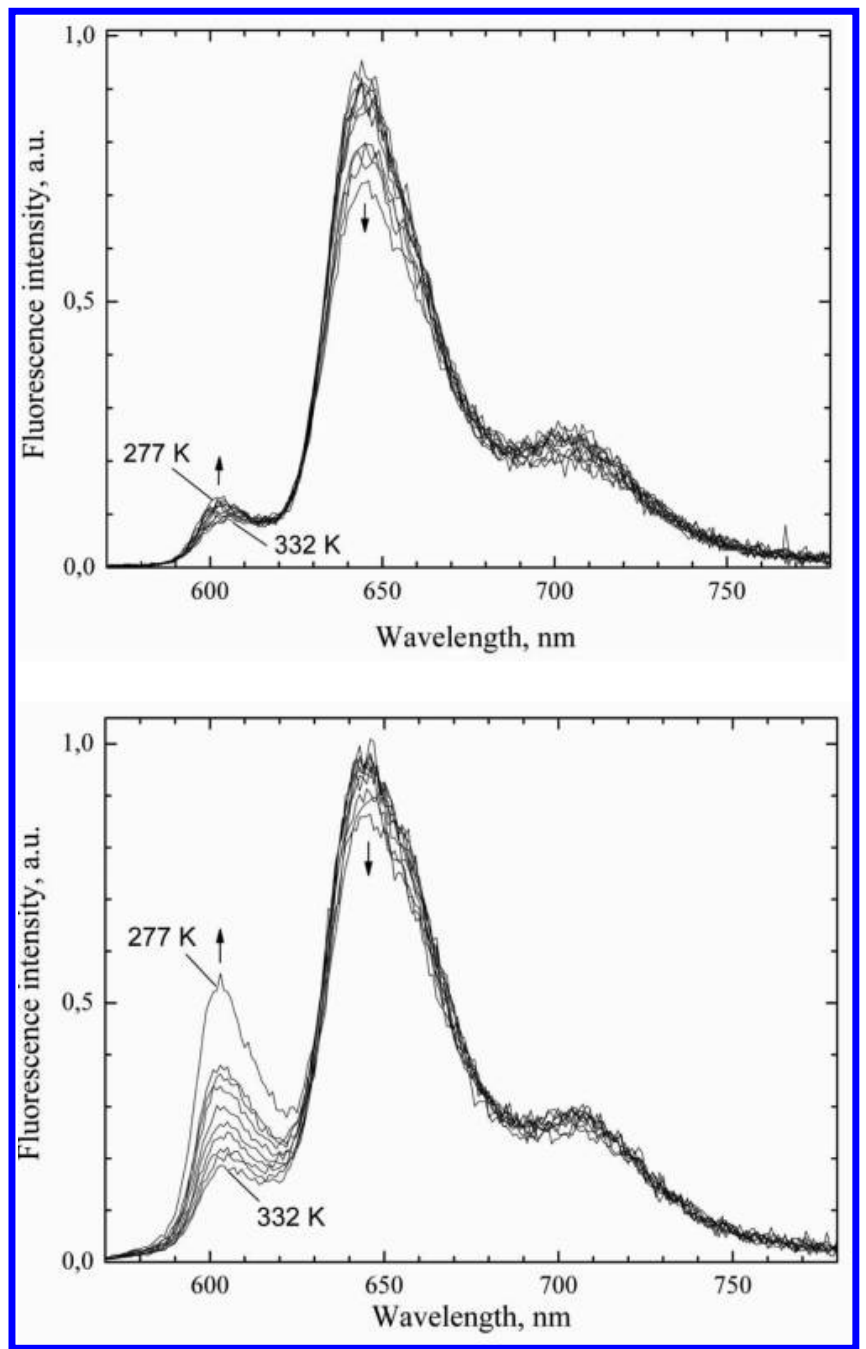

Figure 7. Fluorescence spectra of $\mathrm{Fb}$ meso-pyrimidinylcorrole $\mathrm{H}_{3} \mathrm{AB}_{2}$ measured at different temperatures in the range $277-332 \mathrm{~K}$ in EtOH (top) and EtOD (bottom) $\left(\lambda_{\mathrm{exc}}=480 \mathrm{~nm}\right)$. Arrows indicate the direction of spectral changes upon decreasing temperature.

transition at $605 \mathrm{~nm}$ ) increased dramatically at the expense of the emission from the T1 tautomer (with a maximum of the $S_{1}(0,0) \rightarrow S_{0}(0,0)$ transition at $\left.645 \mathrm{~nm}\right)$ for the $D_{3} A_{2}$-corrole for any temperature value within the range $277-332 \mathrm{~K}$. Second, the temperature dependence of the $\mathrm{NH}$ tautomerization in the excited singlet $S_{1}$ state of the $D_{3} A_{2}$-corrole was stronger, leading to a more than 3 -fold increase in the emission from the T2 tautomer in the studied temperature range, whereas the fluorescence intensity from the T2 tautomer of the $\mathrm{H}_{3} \mathrm{AB}_{2}$ corrole at $277 \mathrm{~K}$ is only about twice of that measured at $332 \mathrm{~K}$. Taking into account the above discussion on the dominating efficiency of the T2 $\rightarrow \mathrm{T} 1$ tautomerization in the deactivation of the excited singlet $S_{1}$ state of the $\mathrm{H}_{3} \mathrm{AB}_{2}$-corrole at room temperature, one can state that the increase in the proportion of the T2 tautomer emission in the total fluorescence spectrum upon deuteration results from a reduced $\mathrm{T} 2 \rightarrow \mathrm{T} 1$ tautomerization rate. As a result, a larger part of the $S_{1}$ state excitation energy deactivates within the T2 tautomer rather than undergoing tautomerization leading to population of the $S_{1}$ state of the T1 tautomer.

This substantial change in the proportion between the $\mathrm{T} 1$ and $\mathrm{T} 2$ tautomers in a relatively narrow temperature range can be used to deduce the fluorescence profiles for the separate $\mathrm{NH}$ 
tautomers. The relatively narrow temperature range is important since there are neither spectral shifts nor changes in the half width of the bands in the fluorescence spectra. Thus, two spectra with substantial differences in the $\mathrm{T} 2$ to $\mathrm{T} 1$ proportion should be used for this procedure, for example, the spectra measured for the $\mathrm{D}_{3} \mathrm{AB}_{2}$-corrole at 295 and $323 \mathrm{~K}$ (Figure 8 ). The spectra are normalized for peak intensity of the

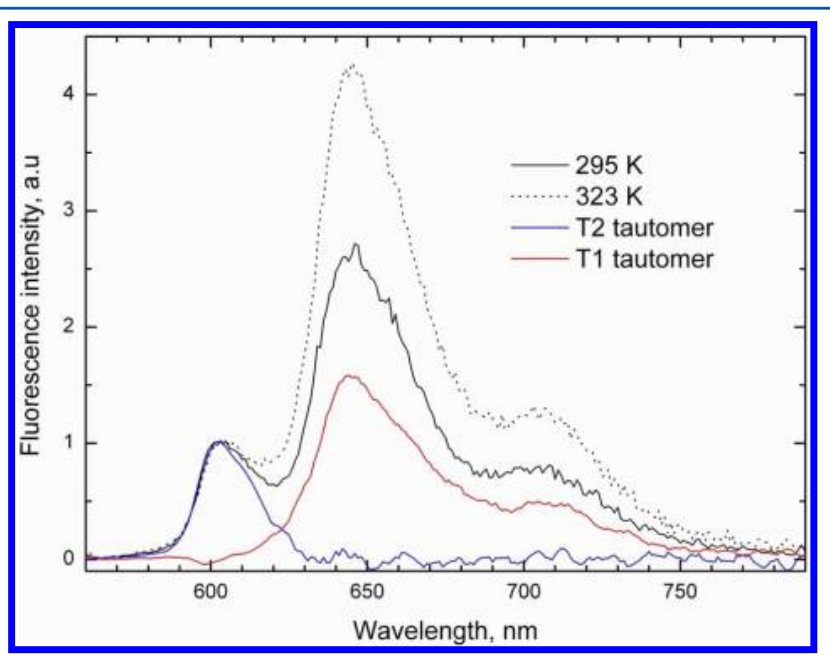

Figure 8. Fluorescence spectra of $\mathrm{Fb}$ meso-pyrimidinylcorrole $\mathrm{H}_{3} \mathrm{AB}_{2}$ in EtOD at $T=295 \mathrm{~K}$ (black solid line) and $323 \mathrm{~K}$ (dotted line) $\left(\lambda_{\text {exc }}\right.$ $=480 \mathrm{~nm}$ ). Spectra are normalized for peak intensity of the band at $605 \mathrm{~nm}$. The fluorescence profile of the T1 tautomer (red line) was obtained as the difference of the two spectra above: $I_{\mathrm{T} 1}=I(323 \mathrm{~K})-$ $\mathrm{I}(295 \mathrm{~K})$. The fluorescence profile of the $\mathrm{T} 2$ tautomer (blue line) was obtained as $I_{\mathrm{T} 2}=I(295 \mathrm{~K})-\alpha I_{\mathrm{T} 1}$, where $\alpha$ is a scaling constant.

band at $605 \mathrm{~nm}$, implying the same concentration of the T2 tautomer emitters (the emission from the $\mathrm{T} 1$ tautomer is negligibly small in this spectral range). Therefore, the difference in these normalized spectra is due to a different amount of T1 tautomer emitters. The fluorescence signature of the T1 tautomer IT1 can then be obtained as the difference of the two normalized spectra $I(323 \mathrm{~K})-I(295 \mathrm{~K})$ (Figure 8 , red line). The fluorescence profile of the T2 tautomer is obtained as $I_{\mathrm{T} 2}=$ $I(295 \mathrm{~K})-\alpha I_{\mathrm{T} 1}$, where $\alpha$ is a scaling constant determined from the fitting procedure (Figure 8 , blue line). The same procedure was applied for the $\mathrm{H}_{3} \mathrm{AB}_{2}$-corrole, and essentially the same spectral profiles were obtained (not shown).

Individual Fluorescence Quantum Yields of the T1 and T2 Tautomers. In the case under consideration, the fluorescence quantum yield $\Phi_{\mathrm{fl}}$ is the overall value for the coexisting $\mathrm{T} 1$ and $\mathrm{T} 2$ tautomer species:

$$
\Phi_{\mathrm{fl}}=\Phi_{\mathrm{fl}}(\mathrm{T} 1) n(\mathrm{~T} 1)+\Phi_{\mathrm{fl}}(\mathrm{T} 2) n(\mathrm{~T} 2)
$$

where $n(\mathrm{~T} 1), n(\mathrm{~T} 2)$ and $\Phi_{\mathrm{fl}}(\mathrm{T} 1), \Phi_{\mathrm{fl}}(\mathrm{T} 2)$ are the relative concentrations and individual fluorescence quantum yields of the $\mathrm{T} 1$ and $\mathrm{T} 2$ tautomers, respectively (with $n(\mathrm{~T} 1)+n(\mathrm{~T} 2)=$ 1 ). It is interesting to analyze the temperature dependence of the overall fluorescence quantum yield $\Phi_{\mathrm{fl}}$ since the ratio of the two NH tautomers in solution is proportional to the temperature. The measured dependencies in both EtOH and EtOD are shown in Figure 9. One can see that a decrease in temperature leads to a substantial increase in the $\Phi_{\mathrm{fl}}$ value in both cases. Since the studied temperature range is rather narrow $(277-332 \mathrm{~K})$, one can expect that there is no temperature dependence of the individual quantum yields of

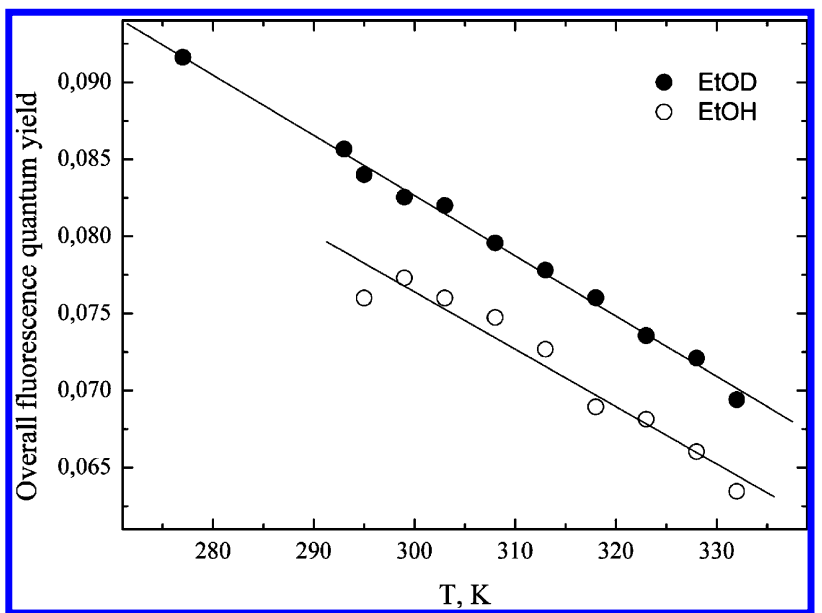

Figure 9. Overall fluorescence quantum yields of $\mathrm{Fb}$ 10-(4,6dichloropyrimidin-5-yl)-5,15-dimesitylcorrole in EtOH and EtOD as a function of temperature. The solid lines represent the linear fits of the experimental data.

the tautomers, and all the changes observed are due to a change in the ratio of T1 and T2 tautomers. As it was shown above, the proportion of the $\mathrm{T} 2$ tautomer increases with decreasing temperature at the expense of $\mathrm{T} 1$, with $\Delta n(\mathrm{~T} 2)=-\Delta n(\mathrm{~T} 1)$. Therefore, the increase in the overall fluorescence quantum yield $\Phi_{\mathrm{fl}}$ unambiguously indicates that the individual fluorescence quantum yield $\Phi_{\mathrm{fl}}(\mathrm{T} 2)$ of the T2 tautomer is higher as compared to the individual fluorescence quantum yield $\Phi_{\mathrm{fl}}(\mathrm{T} 1)$ of the $\mathrm{T} 1$ tautomer.

Above, we have also shown that the emission intensity at 605 $\mathrm{nm}$ is proportional to the concentration of the $\mathrm{T} 2$ tautomer and can be used at its measure, i.e., $n(\mathrm{~T} 2) \approx I(605 \mathrm{~nm}) / \Phi_{\mathrm{fl}}(\mathrm{T} 2)$. Therefore, a plot of the overall fluorescence quantum yield $\Phi_{\mathrm{fl}}$ versus $I(605 \mathrm{~nm})$ can be treated as $\Phi_{\mathrm{fl}}=\mathrm{f}(n(\mathrm{~T} 2))$ (Figure 10). The plots can be nicely fitted with linear functions for both $\mathrm{EtOH}$ and EtOD solutions. According to eq 1, with extrapolation of this dependence to $I(605 \mathrm{~nm})=0$, we approach the limit when $n(\mathrm{~T} 2)=0$ and $n(\mathrm{~T} 1)=1$, i.e., all the

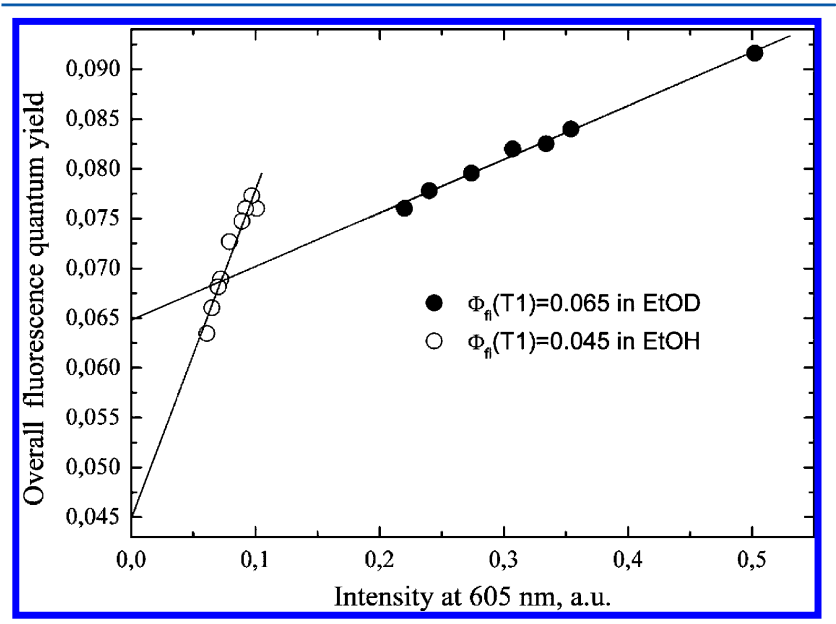

Figure 10. Overall fluorescence quantum yield of $\mathrm{Fb}$ 10-(4,6dichloropyrimidin-5-yl)-5,15-dimesitylcorrole as a function of peak fluorescence intensity of the T2 tautomer at $605 \mathrm{~nm}$. The solid lines represent the linear fits of the experimental data, giving rise to an estimate of the fluorescence quantum yield of the T1 tautomer when it emits solely at $I(605 \mathrm{~nm})=0$. 
emission is due to fluorescence of the T1 tautomer and $\Phi_{\mathrm{fl}}=$ $\Phi_{\mathrm{fl}}(\mathrm{T} 1)$. Via this procedure, $\Phi_{\mathrm{fl}}(\mathrm{T} 1)$ values of $0.045 \pm 0.01$ and $0.065 \pm 0.01$ were estimated for $\mathrm{EtOH}$ and EtOD solutions, respectively. These values indicate that deuteration of three core nitrogen atoms in the $\mathrm{H}_{3} \mathrm{AB}_{2}$-corrole leads to an increase in the fluorescence efficiency of the $\mathrm{T} 1$ tautomer.

The difference in the overall fluorescence intensity for two temperatures (for example, let us consider the same case as shown in Figure 8 for $\mathrm{D}_{3} \mathrm{AB}_{2}$ ) is

$$
\Delta I=I(295 \mathrm{~K})-I(323 \mathrm{~K})=\Delta I(\mathrm{~T} 2)-\Delta I(\mathrm{~T} 1)
$$

Using eq 1 , one can rewrite eq 2 as

$$
\Delta I=\Phi_{\mathrm{fl}}(\mathrm{T} 2) \Delta n(\mathrm{~T} 2)-\Phi_{\mathrm{fl}}(\mathrm{T} 1) \Delta n(\mathrm{~T} 1)
$$

but $\Delta n(\mathrm{~T} 2)=\Delta n(\mathrm{~T} 1)=\Delta n$, therefore, one can simplify eq3:

$$
\Delta I=\Phi_{\mathrm{fl}}(\mathrm{T} 2) \Delta n-\Phi_{\mathrm{fl}}(\mathrm{T} 1) \Delta n
$$

By combining eqs 2 and 4, a simple system of equations can be written, which allows excluding the unknown value $\Delta n$ and solving this system with respect to $\Phi_{\mathrm{fl}}(\mathrm{T} 2)$ :

$$
\begin{aligned}
& \Delta I(\mathrm{~T} 2)=\Phi_{\mathrm{fl}}(\mathrm{T} 2) \Delta n \\
& \Delta I(\mathrm{~T} 1)=\Phi_{\mathrm{fl}}(\mathrm{T} 1) \Delta n
\end{aligned}
$$

Then, from eqs 5 and 6 :

$$
\Phi_{\mathrm{fl}}(\mathrm{T} 2)=(\Delta I(\mathrm{~T} 2) / \Delta I(\mathrm{~T} 1)) \Phi_{\mathrm{fl}}(\mathrm{T} 1)
$$

By substituting in eq 7 , the known value of $\Phi_{\mathrm{fl}}(\mathrm{T} 1)$ and the $\Delta I(\mathrm{~T} 2)$ and $\Delta I(\mathrm{~T} 1)$ values calculated from deconvolution of the experimental spectra with the fluorescence profiles of the $\mathrm{T} 1$ and $\mathrm{T} 2$ tautomers, a value of $\Phi_{\mathrm{fl}}(\mathrm{T} 2)=0.175 \pm 0.01$ was calculated for the $\mathrm{D}_{3} \mathrm{AB}_{2}$-corrole.

One can rewrite eq 1 as

$$
\Phi_{\mathrm{fl}}=\left(\Phi_{\mathrm{fl}}(\mathrm{T} 2)-\Phi_{\mathrm{fl}}(\mathrm{T} 1)\right) \Delta n+\Phi_{\mathrm{fl}}(\mathrm{T} 1)
$$

where $\Delta n$ possesses values from 0 to 1 . One can see that the slope of the function $\Phi_{\mathrm{fl}}=\mathrm{f}(\Delta n)$ is defined as the difference $\Phi_{\mathrm{fl}}(\mathrm{T} 2)-\Phi_{\mathrm{fl}}(\mathrm{T} 1)$. As it was shown above, the $\Delta n$ and temperature $T$ hold a linear relationship. Therefore, the plot shown in Figure 9 can be considered as $\Phi_{\mathrm{fl}}=\mathrm{f}(\Delta n)$. The same slope observed for both the EtOD and EtOH solutions indicates the same value $\Phi_{\mathrm{fl}}(\mathrm{T} 2)-\Phi_{\mathrm{fl}}(\mathrm{T} 1)=0.11$. Thus, $\Phi_{\mathrm{fl}}(\mathrm{T} 2)=0.155 \pm 0.01$ can be estimated with 8 for the $\mathrm{H}_{3} \mathrm{AB}_{2}-$ corrole. On the basis of all these findings and using 8 , we can estimate the proportion of the emitting $\mathrm{T} 1$ and $\mathrm{T} 2$ tautomer species in the singlet $S_{1}$ state of the studied corrole at different temperatures. For example, all the spectral changes observed in Figure 7 for the $\mathrm{D}_{3} \mathrm{AB}_{2}$-corrole are due to an increase in the T2 tautomer proportion from 0.04 at $332 \mathrm{~K}$ up to 0.24 at $277 \mathrm{~K}$.

Finally, the fluorescence quantum yield for the T2 tautomer was measured directly in a separate experiment in a glassy solid solution (in 2-Me-THF) at $77 \mathrm{~K}$. The obtained value $\Phi_{\mathrm{fl}}(\mathrm{T} 2)_{77 \mathrm{~K}}=0.23 \pm 0.046$ fits well to the estimated value at room temperature (vide supra). Minor differences in the fluorescence quantum yields seem to reflect possible changes in the rates of intramolecular deactivation pathways upon going from room temperature to $77 \mathrm{~K}$ since the fluorescence spectrum underwent a noticeable blue shift and the Stokes shift disappeared (see above, Figures 2 and 3).

\section{CONCLUSIONS}

An experimental study has been undertaken to disclose the individual fluorescence profiles of the two $\mathrm{NH}$ tautomers of 10(4,6-dichloropyrimidin-5-yl)-5,15-dimesitylcorrole. The bands in the fluorescence spectra at room temperature and below have been assigned to the individual $\mathrm{NH}$ tautomers. The Stokes shift between the peaks of the $0-0$ transition in absorbance and fluorescence at room temperature was found to be larger for the long wavelength $\mathrm{T} 1$ tautomer compared to the short wavelength $\mathrm{T} 2$ tautomer $\left(270 \mathrm{~cm}^{-1}\right.$ vs $\left.165 \mathrm{~cm}^{-1}\right)$, indicating that the $\mathrm{T} 1$ tautomer structure seems to be more flexible and undergoes slightly larger rearrangements in the excited singlet $\mathrm{S}_{1}$ state as compared to the T2 tautomer. At low temperatures $(4.2-77 \mathrm{~K})$, the solid solution prevents conformational relaxation, and no Stokes shift was observed. It was found that the fluorescence from the long wavelength $\mathrm{T} 1$ tautomer dominates in the total emission spectrum at room temperature, in contrast to the situation at low temperatures, where the short wavelength T2 tautomer dominates. This phenomenon of temperature-controlled switching between the fluorescence emissions from the two corrole $\mathrm{NH}$ tautomers is observed for the first time and was explained by a reduced $\mathrm{T} 2 \rightarrow \mathrm{T} 1$ tautomerization rate with a decrease in temperature. Energy level diagrams explaining the excitation energy deactivation channels at different temperatures are proposed.

$\mathrm{H} / \mathrm{D}$ substitution of the core pyrroles also leads to a substantial decrease in the $\mathrm{NH}$ tautomerization rate, resulting in an increase in the contribution of the $\mathrm{T} 2$ tautomer to the total fluorescence spectrum at the expense of the T1 tautomer. A temperature dependence of the fluorescence spectra in the temperature range $277-332 \mathrm{~K}$ was observed and used to evaluate the spectral profiles for the individual $\mathrm{NH}$ tautomers. The pronounced increase in the overall fluorescence quantum yield upon going from 332 to $277 \mathrm{~K}$ was explained in terms of the difference in fluorescence quantum yields of the individual tautomers. The fluorescence quantum yield of the $\mathrm{T} 1$ tautomer was found to be as low as 0.045 and 0.065 in EtOH and EtOD solutions, respectively. However, values of 0.155 and 0.175 were calculated for the $\mathrm{T} 2$ tautomer (all these values refer to the temperature range $277-332 \mathrm{~K}$ ).

In summary, the fluorescence data presented here bring additional unambiguous proof for the coexistence of two corrole $\mathrm{NH}$ tautomers in fluid and solid solutions in a wide temperature range. The results allow clarifying previously observed problems in the interpretation of the fluorescence spectra of both meso-pyrimidinylcorroles and, in a more general sense, the whole family of meso-triarylcorroles, as well as on the understanding of their luminescence properties as a function of temperature.

\section{AUTHOR INFORMATION}

\section{Corresponding Author}

*(M.K.) Tel: (+375) 17284 1563. Fax: (+375) 172840679. E-mail: kruk@imaph.bas-net. (W.M.) Tel: (+32) 11268312. Fax: (+32) 11 268299. E-mail: wouter.maes@uhasselt.be.

\section{Author Contributions}

The manuscript was written through contributions of all authors. All authors have given approval to the final version of the manuscript.

\section{Notes}

The authors declare no competing financial interest. 


\section{ACKNOWLEDGMENTS}

This work has been carried out with financial support from FP7 project DphotoD-PEOPLE-IRSES-GA-2009-247260. The State Program of Scientific Research "Convergence" of the Republic of Belarus (project 3.1.03) is acknowledged by M.K. and A.S. W.M., T.H.N., and W.D. thank the FWO (Fund for Scientific Research, Flanders), the KU Leuven, and the Ministerie voor Wetenschapsbeleid for continuing financial support. P.V. thanks the IWT (Institute for the Promotion of Innovation through Science and Technology in Flanders) for a doctoral fellowship. T.H.N. acknowledges the IWT and the Alexander von Humboldt Foundation for a doctoral and postdoctoral fellowship, respectively. The authors thank Dr. V. Knyukshto (B.I. Stepanov Institute of Physics) for his invaluable help in the low-temperature emission measurements.

\section{REFERENCES}

(1) Reviews on corrole applications: (a) Aviv, I.; Gross, Z. Chem. Commun. 2007, 1987-1999. (b) Flamigni, L.; Gryko, D. T. Chem. Soc. Rev. 2009, 38, 1635-1646. (c) Aviv-Harel, I.; Gross, Z. Chem.-Eur. J. 2009, 15, 8382-8394. (d) Aviv-Harel, I.; Gross, Z. Coord. Chem. Rev. 2011, 255, 717-736.

(2) (a) Barbe, J.-M.; Canard, G.; Brandès, S.; Guilard, R. Chem.-Eur. J. 2007, 13, 2118-2129. (b) Mahammed, A.; Gross, Z. Chem. Commun. 2010, 7040-7042. (c) Kupershmidt, L.; Okun, Z.; Amit, T.; Mandel, S.; Saltsman, I.; Mahammed, A.; Bar-Am, O.; Gross, Z.; Youdim, M. B. H. J. Neurochem. 2010, 113, 363-373. (d) Abu-Omar, M. M. Dalton Trans. 2011, 40, 3435-3444. (e) Suranjana Bose, S.; Pariyar, A.; Biswas, A. N.; Das, P.; Bandyopadhyay, P. Catal. Commun. 2011, 12, 446-449. (f) Dogutan, D. K.; McGuire, R.; Nocera, D. G. J. Am. Chem. Soc. 2011, 133, 9178-9180. (g) Flamigni, L.; Ciuciu, A. I.; Langhals, H.; Böck, B.; Gryko, D. T. Chem. Asian J. 2012, 7, 582-592.

(3) Reviews on (synthetic) corrole chemistry: (a) Gryko, D. T. Eur. J. Org. Chem. 2002, 1735-1743. (b) Gryko, D. T.; Fox, J. P.; Goldberg, P. J. Porphyrins Phthalocyanines 2004, 8, 1091-1105. (c) Ghosh, A. Angew. Chem., Int. Ed. 2004, 43, 1918-1931. (d) Nardis, S.; Monti, D.; Paolesse, R. Mini-Rev. Org. Chem. 2005, 2, 355-374. (e) Paolesse, R. Synlett 2008, 2215-2230. (f) Gryko, D. T. J. Porphyrins Phthalocyanines 2008, 12, 906-917. (g) Lemon, C. M.; Brothers, P. J. J. Porphyrins Phthalocyanines 2011, 15, 809-834.

(4) Studies on free-base corrole photophysics (see also refs 1b, 2g, 5c, and 5e): (a) Paolesse, R.; Sagone, F.; Macagnano, A.; Boschi, T.; Prodi, L.; Montalti, M.; Zaccheroni, N.; Bolletta, F.; Smith, K. M. J. Porphyrins Phthalocyanines 1999, 3, 364-370. (b) Bendix, J.; Dmochowski, I. J.; Gray, H. B.; Mahammed, A.; Simkhovich, L.; Gross, Z. Angew. Chem., Int. Ed. 2000, 39, 4048-4051. (c) Paolesse, R.; Marini, A.; Nardis, S.; Froiio, A.; Mandoj, F.; Nurco, D. J.; Prodi, L.; Montalti, M.; Smith, K. M. J. Porphyrins Phthalocyanines 2003, 7, 25-36. (d) Ding, T.; Harvey, J. D.; Ziegler, C. J. J. Porphyrins Phthalocyanines 2005, 9, 22-27. (e) Ding, T.; Aleman, E. A.; Modarelli, D. A.; Ziegler, C. J. J. Phys. Chem. A 2005, 109, 74117417. (f) Ventura, B.; Degli Esposti, A.; Koszarna, B.; Gryko, D. T.; Flamigni, L. New J. Chem. 2005, 29, 1559-1566. (g) Poulin, J.; Stern, C.; Guilard, R.; Harvey, P. D. Photochem. Photobiol. 2006, 82, 171176. (h) Gross, Z.; Gray, H. B. Comments Inorg. Chem. 2006, 27, 6172. (i) Gros, C. P.; Brisach, F.; Meristoudi, A.; Espinosa, E.; Guilard, R.; Harvey, P. D. Inorg. Chem. 2007, 46, 125-135. (j) Flamigni, L.; Ventura, B.; Tasior, M.; Gryko, D. T. Inorg. Chim. Acta 2007, 360, 803-813. (k) Tasior, M.; Gryko, D. T.; Cembor, M.; Jaworski, J. S.; Ventura, B.; Flamigni, L. New J. Chem. 2007, 31, 247-259. (1) Flamigni, L.; Ventura, M.; Tasior, M.; Becherer, T.; Langhals, H.; Gryko, D. T. Chem.-Eur. J. 2008, 14, 169-183. (m) D'Souza, F.; Chitta, R.; Ohkubo, K.; Tasior, M.; Subbaiyan, N. K.; Zandler, M. E.; Rogacki, M. K.; Gryko, D. T.; Fukuzumi, S. J. Am. Chem. Soc. 2008, 130, 14263-14272. (n) Tasior, M.; Gryko, D. T.; Shen, J.; Kadish, K. M.; Becherer, T.; Langhals, H.; Ventura, B.; Flamigni, L. J. Phys. Chem. C 2008, 112, 19699-19709. (o) Shi, L.; Liu, H.-Y.; Shen, H.; Hu, J.;
Zhang, G.-L.; Wang, H.; Ji, L.-N.; Chang, C.-K.; Jiang, H.-F. J. Porphyrins Phthalocyanines 2009, 13, 1221-1226. (p) You, L. L.; Shen, H.; Shi, L.; Zhang, G. L.; Liu, H. Y.; Wang, H.; Ji, L. N. Sci. China, Ser. G: Phys., Mech. Astron. 2010, 53, 1491-1496. (q) Tasior, M.; Gryko, D. T.; Pielacinska, D. J.; Zanelli, A.; Flamigni, L. Chem.-Asian J. 2010, 5, 130-140. (r) Shi, L.; Liu, H.-Y.; Peng, K.-M.; Wang, X.-L.; You, L.L.; Lu, J.; Zhang, L.; Wang, H.; Ji, L.-N.; Jiang, H.-F. Tetrahedron Lett. 2010, 51, 3439-3442. (s) Flamigni, L.; Wyrostek, D.; Voloshchuk, R.; Gryko, D. Phys. Chem. Chem. Phys. 2010, 12, 474-483.

(5) (a) Maes, W.; Ngo, T. H.; Vanderhaeghen, J.; Dehaen, W. Org. Lett. 2007, 9, 3165-3168. (b) Ngo, T. H.; Van Rossom, W.; Dehaen, W.; Maes, W. Org. Biomol. Chem. 2009, 7, 439-443. (c) Ngo, T. H.; Puntoriero, F.; Nastasi, F.; Robeyns, K.; Van Meervelt, L.; Campagna, S.; Dehaen, W.; Maes, W. Chem.-Eur. J. 2010, 16, 5691-5705. (d) Ngo, T. H.; Nastasi, F.; Puntoriero, F.; Campagna, S.; Dehaen, W.; Maes, W. J. Org. Chem. 2010, 75, 2127-2130. (e) Nastasi, F.; Campagna, S.; Ngo, T. H.; Dehaen, W.; Maes, W.; Kruk, M. Photochem. Photobiol. Sci. 2011, 10, 143-150.

(6) Ivanova, Y. B.; Savva, V. A.; Mamardashvili, N. Z.; Starukhin, A. S.; Ngo, T. H.; Dehaen, W.; Maes, W.; Kruk, M. M. J. Phys. Chem. A 2012, DOI: $10.1021 /$ jp305325e, companion article.

(7) Kruk, M. M.; Starukhin, A. S.; Czerwieniec, R. J. Porphyrins Phthalocyanines 2008, 12, 1201-1210.

(8) Knyukshto, V. N.; Shulga, A. M.; Zenkevich, E. I.; Sagun, E. I.; Bachilo, S. M. Chem. Phys. Lett. 1998, 297, 97-108.

(9) Beenken, W. J. D.; Presselt, M.; Maes, W.; Ngo, T. H.; Dehaen, W.; Starukhin, A. S.; Kruk, M. M., manuscript to be submitted.

(10) (a) Gentemann, S.; Medforth, C. J.; Forsyth, T. P.; Nurco, D. J.; Smith, K. M.; Fajer, J.; Holten, D. J. Am. Chem. Soc. 1994, 116, 73637368. (b) Shelnutt, J. A.; Song, X.-Z.; Ma, J.-G.; Jia, S.-J.; Jentzen, W.; Medforth, C. J. Chem. Soc. Rev. 1998, 27, 31-41.

(11) Balazs, Y. S.; Saltsman, I.; Mahammed, A.; Tkachenko, E.; Golubkov, G.; Levine, J.; Gross, Z. Magn. Reson. Chem. 2004, 42, 624635.

(12) (a) Gross, Z.; Galili, N. Angew. Chem., Int. Ed. 1999, 38, 23662369. (b) Simkhovich, L.; Iyer, P.; Goldberg, I.; Gross, Z. Chem.-Eur. J. 2002, 8, 2595-2601.

(13) During final redaction of this article, Nemykin et al. have also reported on a tentative $\mathrm{NH}$ tautomer assignment (based on MCD and TDDFT calculations), in line with our conclusions: Ziegler, C. J.; Sabin, J. R.; GeierR. , G., III; Nemykin, V. N. Chem. Commun. 2012, $48,4743-4745$.

(14) (a) Solovyov, K. N.; Gladkov, L. L.; Starukhin, A. S.; Shkirman, S. F. Spectroscopy of Porphyrins: Vibrational States; Science and Technique: Minsk, Belarus, 1985; p 415 (in Russian). (b) Engst, P.; Kubat, P.; Jirsa, M. J. Photochem. Photobiol., A 1994, 78, 215-219. 